\title{
Article
}

\section{Psychosis and Human Rights: Conflicts in Mental Health Policy and Practice}

Spandler, Helen and Calton, Tim

Available at http://clok.uclan.ac.uk/1988/

Spandler, Helen ORCID: 0000-0002-0970-5141 and Calton, Tim (2009)

Psychosis and Human Rights: Conflicts in Mental Health Policy and Practice.

Social Policy and Society, 8 (2). pp. 245-256. ISSN 1474-7464

It is advisable to refer to the publisher's version if you intend to cite from the work. http://dx.doi.org/10.1017/S1474746408004764

For more information about UCLan's research in this area go to

http://www.uclan.ac.uk/researchgroups/ and search for <name of research Group>.

For information about Research generally at UCLan please go to

http://www.uclan.ac.uk/research/

All outputs in CLoK are protected by Intellectual Property Rights law, including Copyright law. Copyright, IPR and Moral Rights for the works on this site are retained by the individual authors and/or other copyright owners. Terms and conditions for use of this material are defined in the policies page.

\section{CLoK}

Central Lancashire online Knowledge www.clok.uclan.ac.uk

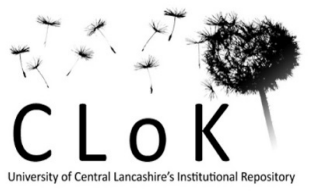




\title{
Psychosis and Human Rights: Conflicts in Mental Health Policy and Practice
}

\author{
Helen Spandler* and Tim Calton** \\ * School of Social Work, University of Central Lancashire \\ E-mail: HSpandler@uclan.ac.uk \\ ** Institute of Mental Health, University of Nottingham
}

This paper examines conflicts in polices in England and Wales pertaining to the demand for alternative, non-medical crisis support for those experiencing 'psychosis'. We examine the limitations of current treatment, policy and legislative frameworks in supporting these demands. In particular, we focus on the limitations of prevailing conceptualisations of 'human rights', 'social inclusion' and 'recovery'. These concepts, we argue, are embedded within a broader treatment framework which renders medication as mandatory and all other treatment modalities as inherently subsidiary, and a broader policy framework which is complicit with bio-medical orthodoxies of 'mental illness' and prioritises treatment compliance and compulsion. Therefore, in order to advance a 'human rights' approach to mental health policy, we argue that reigning orthodoxies inherent within policy and practice must be explicitly challenged to open up spaces for the availability of alternatives.

\section{Introduction: mental health policy and human rights}

Social policy in mental health is informed by a dominant psychiatric epistemology which prefers to understand 'psychosis' ${ }^{1}$ as a symptom of an acute and/or severe and enduring mental illness, resulting from a bio-chemical imbalance in the brain which requires expert psychiatric treatment, including neuroleptic medication (also known as 'antipsychotics'). Various challenges have been mounted to this understanding of 'psychotic experience', both from inside and outside the psychiatric profession, primarily from service user groups and some dissident professionals. As a result, psychosis has been viewed as a variant of 'normal' human experience, which can be understood within a person's life experiences and contexts (Bentall, 2004). Some have even challenged the view that psychosis itself exists as a distinct and identifiable experience (Boyle, 2006); and others have sought alternative ways of viewing these experiences, for example, as a 'non-ordinary' or 'extra-ordinary' state of consciousness (Plumb, 1999) or as representing an existential, spiritual or psychological crisis (Clarke, 2001) or a reaction to trauma (Read et al., 2005).

Such alternative frameworks tend to share a conviction that psychosis is ineluctably meaningful, representing a powerful mediator of human experience, especially in relation to oneself, one's surroundings and relationships. The potential utility of alternative epistemological frameworks are supported by research, suggesting service users frequently want to discuss the content of their 'psychotic experiences' and search for their meaning 
and significance outside of bio-medical frameworks (McCabe, 2002; Larsen, 2004). Some commentators go further and maintain that medication may actually prevent learning, recovery and healing (Stastny and Lehmann, 2007). The service user/survivor movement as a whole, whilst eschewing a firm 'position' on psychiatric medication, has consistently demanded access to drug-free alternative provision for people in crisis (Campbell, 2000). In fact, this has been a consistent demand since the inception of the users/survivors movement over 30 years ago and has been regarded as a human rights issue:

There is only one way to safeguard our rights and to provide genuinely sound and effective services. This is the pioneering of, provision and resourcing of non-medical sanctuary and support without drug treatment for a person during, and following a crisis, where consent to medical treatment is not given. This is what genuinely new legislation should be about. (Plumb, 1999: 463, emphasis in original)

Framed in this way, it can be viewed as an example which crosscuts all three 'generations' of human rights (Vasak, 1982). 'First generation' rights are often conceived as 'negative rights', e.g. individual freedom from repressive state intervention. We can include here psychiatric coercion and intervention without consent (neuroleptic medication is the most common medication to be given without consent). Indeed forced treatment has been seen to violate the Universal Declaration of Human Rights, article 5, which states that 'no-one shall be subject to torture or to cruel, inhuman or degrading treatment or punishment' (Derbyshire Voice, 2008: 35). 'Second generation' rights are conceived as 'positive' or 'welfare' rights, e.g. the freedom of individuals to receive economic, social and health support provided by the State. Here we can include the provision of adequate welfare support in times of acute crisis/psychosis. Finally, 'third generation' rights are more complex, contentious and harder to legally enforce, but are usually seen as environmental, solidaristic and include the right to 'self-determination'. Cresswell (in this volume) has made a convincing case for including 'experiential rights' as a singular example of third generation rights, based upon experiential claims by the service user/survivor movement.

So, this paper explores the right to experience psychosis (third generation), without forced treatment/medication (first generation), but with maximum support (second generation). Focusing on England and Wales, we contextualise this demand and the surrounding debates within extant policy frameworks. First, we examine the prevailing treatment context in order to fully appreciate the current relevance of this 'rights-based' claim. Second, we explore the possibilities and limitations of human rights legislation in supporting such demands. Finally, we highlight the limitations of recent social policy directives in mental health, focusing on current conceptualisations of 'recovery' and 'inclusion'.

\section{The treatment framework}

The importance attached to the prescribing and management of psychiatric medication, especially neuroleptics, continues to dominate community mental health policy, especially for people with a diagnosis of schizophrenia. As a result, treatment 'noncompliance', especially with neuroleptics, has become a key policy concern as it is considered a 'threat' to the legitimation, functioning and success of post-war policies of 
'community care' (Rogers et al., 1998; Rogers and Pilgrim, 2001). Indeed, the psychiatric treatment of people diagnosed with schizophrenia continues to rely almost entirely on the (sometimes involuntarily) use of antipsychotic medication. The National Institute for Clinical Excellence (NICE) in the UK, a government body attached to the Department of Health, insists that medication is necessary and indispensable in acute psychosis, a mandate not extended to psycho-social interventions (NICE, 2002). More than this, the National Service Framework recommends that psychosis should be anticipated or prevented and that any delay in the use of medication can lead to poorer outcomes $(\mathrm{DoH}, 1999 \mathrm{~b})$. Indeed, the current focus of policy guidelines in relation to psychosis recommends medical intervention at the earliest signs of psychosis and even before the person has actually exhibited any psychotic symptoms, but are considered 'at risk' of doing so. As a result 'early intervention in psychosis' teams are now a key feature of modern mental health provision in England, as well as other countries (Warner, 2008).

However, the evidence as to the effectiveness of 'early intervention' is at best weak and at worst non-existent (Warner, 2008). Moreover, such practices raise a number of 'human rights' issues regarding the potential of exposing people to a psychiatric career, the inherent uncertainties regarding prognosis and the administration of drugs with potentially harmful side-effects to people who may not go on to develop psychosis (Bentall and Morrison, 2002). Whilst it is probably undeniable that anti-psychotics may benefit significant numbers of people by reducing unwanted and distressing symptoms, policy guidelines which rest on the presumed necessity and primacy of anti-psychotic medications have increasingly been criticised. World Health Organisation figures suggest that 'recovery rates' from schizophrenia are better in developing countries which do not use such treatments to the same extent, if at all (Hopper et al., 2004), and it has been suggested that recovery rates in the west are not actually increasing, but may even be decreasing despite the introduction of new anti-psychotics (Warner, 2004). In addition, a significant number of people who experience psychosis do not benefit from medication (a category known as 'persistent neuroleptic non-responders'); some may benefit as much, if not more, from drug free alternatives; and others may recovery anyway, with adequate social support (Warner, 2004). Despite studies suggesting that medication is not always essential for good outcomes in the treatment of people exhibiting first episode psychosis or 'schizophrenia-like' illness, drug-free strategies are rarely, if ever, considered by modern psychiatric services (Calton et al., 2008; Calton and Spandler, 2009).

It is often argued that the benefits of neuroleptics have been exaggerated, leading to an over-reliance upon them and the, perhaps inevitable, consequence of patients experiencing serious 'side-effects', the most notable of these being Tardive Dyskinesia, an irreversible neurological problem resulting in often distressing involuntary movements of the face and limbs (Brown and Funk, 1986). Whilst newer 'atypical' anti-psychotics have been introduced to reduce some unwanted 'side-effects', they have created new, often equally unpleasant, side-effects (Moncrieff, 2007). However, patients' complaints about the 'secondary mental illness' caused by medical intervention (iatrogenic harm) are frequently interpreted as a facet of their putative 'disorder', arising from a 'lack of insight' or a 'symptom' of the underlying disease. As a result, people who refuse to take medication are often seen as uncooperative or delinquent and psychiatrists who minimise prescribing have been viewed as negligent (Double, 2004). In this context, we have seen an increased focus on ensuring treatment and medication compliance. Research, often funded by pharmaceutical companies, explores 'hierarchies of treatment pressures' to 
ensure medication compliance, which includes persuasion, leverage, inducement, threat and compulsion (Sheehan and Molodynski, 2007). In practice, patient compliance is often mediated by real as well as perceived threats of coercion and detention which mean that patients 'internalise' the necessity of medication (Rogers et al., 1998).

Therefore, modern community care policies are predicated not only upon the efficacy of medication, but also the ability of psychiatric services to use compulsion, and in particular, to enforce medication compliance. Whilst there have been some moves to develop greater negotiation about medication between psychiatrists and clients, such as 'concordance' rather than 'compliance', the necessity of medication remains a strong presumption. Indeed enforcing compliance was a prime motivator of the current revisions to the UK's Mental Health Act (2007), which was viewed as a necessary component of making 'modern' mental health policy commensurate with 'community care', i.e. ensuring that patients receive treatment in the 'community', as well as in hospital. ${ }^{2}$ Paul Boetang, the then-Parliamentary Under Secretary for Health, made this motive clear by declaring 'non-compliance can no longer be an option ... this is non-negotiable' (DoH, 1999c).

However, it can be argued that the focus on compliance and compulsion directly contravenes notions of 'patient choice' so central to government health policy $(\mathrm{DoH}$, 1999b; DoH, 2003) More specifically, it can be argued that the provision of services which treat medication as something to be taken voluntarily from a position of informed choice, without the overt or tacit compulsion encountered in standard treatment settings, is a necessary ingredient of patient choice (Calton et al., 2008). However, choice in this context is often severely limited, e.g. to having some say over which antipsychotic is prescribed. It can further be argued that the insistence on medication reveals psychiatry's instrumental role in the instantiation of biopower via its prescription of the conditions of certain forms of human life. In this context, choice becomes an emphatically human rights issue. With this in mind, the following section examines the possibilities and limitations of human rights-based legislation.

\section{The human rights framework}

We have argued that 'psychosis' might be conceived of as a human rights issue, especially as it pertains to enforced treatment and choice, thus pertaining to 'first' and 'second generation' rights. However, this human rights claim also rests on the idea of psychosis being part of the continuum of 'human experience', thus pertaining to 'third generation' rights, a component of which might be termed 'experiential rights' (Cresswell, in this volume). Whilst human rights discourse represents a powerful rallying point for developing progressive policy and practice in mental health (Carpenter, in this volume), there are a number of problems with current human rights legislation demarcating the present zone of contestation. In particular, such legislation offers a problematic framework for these rights-based demands because it places 'mental illness' (or 'psychosis') as explicitly outside the realm of 'human experience' and thus outside the parameters of 'human rights'.

For example, although human rights legislation supposedly asserts a 'universalist' approach to human rights and thus assists in the possible assertion of 'particularistic' rights, they are hampered by specific notions about 'mental illness' embedded within such legislation. These notions prevent the application of 'rights' to some categories of people, including those considered of 'unsound mind' (Gottstein, 2007). As a result, 
human rights legislation actually operates 'exceptionalist' rather than 'universalist' criteria because people with 'mental disorder' operate as a 'limit figure' to the universalist claims of 'human' rights (Cadman, 2006). Whilst such exceptions have been justified in terms of medical paternalism, there is a case to be made that not everyone is guaranteed 'rights' by virtue of being 'human' (Cadman, 2006). For example, some argue that human rights legislation 'harbours old prejudices against those with mental illness' as it remains 'highly deferential to mental health authorities' (Bindman et al., 2003: 91). This is because the Mental Health Act (1983, and its 2007 amendments) 'trumps' the Human Rights Act (Thomas and Thomas, 2004) as well as other potentially progressive pieces of legislation. For example, whilst the Mental Capacity Act (MCA, 2005) states that, regardless of diagnosis, no individual should, a priori, be assumed to lack capacity to make treatment-related decisions, and capacity should be determined on a case-by-case basis, this right is waived once an individual becomes subject to the powers of the Mental Health Act.

People with physical illnesses can be subjected to medical treatment without their consent only if they can be shown to lack treatment-related decisional capacity. Whilst there is significant evidence that most people with 'mental disorder' are actually capable of making treatment decisions (Cairns et al., 2005), treatment can be legally enforced under the auspices of the Mental Health Act (Szmukler, 2004). ${ }^{3}$ It is also the case that patients with a diagnosis of schizophrenia have been shown to make accurate assessments of the effects of medication (Day et al., 1995). Despite this, patients' capacity to make treatment decisions is 'essentially ignored' (Bindman et al., 2003: 91) and 'not given the same respect as that of other patients' (Szmukler, 2004: 17).

These examples expose the limitations of demands which rely on rights-based conceptions because of the 'modalities of exception' articulated in human rights legislation (Parr, 2008: 175). In this context, some patient groups and activists advocate 'strategic litigation' (Gottstein, 2007: 315) to demand the enforcement of universalistic and particularistic legal rights. Such appeals to human rights law have yielded mixed results. For example, a case brought by a patient under compulsory treatment in the UK, who argued for a period free of anti-psychotic medication, resulted in a ruling that clinicians have to give 'written reasons' for particular compulsory treatments (Thomas and Thomas, 2004). Whilst this ruling will increasingly require professionals to justify their actions, 'in human rights terms' (ibid.: 22), the fundamental presupposition that medical treatment is necessary remains unquestioned. Indeed, most Human Rights gains in mental health have focused primarily on procedural issues regarding detention, rather than the more medically dominated issues relating to treatment or access to alternative services and support. As such, it can be argued that neither the broader concept of welfare rights or 'positive rights' (Dean, 2008) nor the new concept of 'experiential rights' have significantly impacted on prevailing human rights debates.

However, there have been some examples of potential changes to welfare provision, through localised human rights activism outside the UK. Such human rights activism is not only designed to prevent coercion ('negative' or 'first generation' rights), but also to act as an impetus to, and mechanism for, creating alternative support ('positive', 'second generation' or 'welfare rights') to develop one's own understanding of 'psychotic experience' ('experiential rights'). For example, in 2003, the organisation PsychRights in Alaska successfully contested a patient's right to be exempt from compulsory treatment and be provided with a non-medical alternative (Gottstein, 2007). This result helped 
initiate the development of a new service for people experiencing psychosis modelled on the 'Soteria paradigm'. ${ }^{4}$ It is unclear whether such strategies will impact on human rights legislation or psychiatric practice in the UK. Indeed psychiatric practice has thus far been more influenced by the reigning social policy framework within which services are developed.

\section{The policy framework: recovery and inclusion}

As we have seen, it is possible that the human rights agenda may indirectly influence the mental health field through the specific litigious efforts of campaigning groups and individuals. At the same time, we have witnessed the re-emergence and consolidation of a number of key concepts such as recovery and social inclusion which are directly influencing mental health policy and practice in the UK and elsewhere, especially in the US, Australia and New Zealand (SCIE, 2007). Both concepts have helped define the direction of local and national mental health policies and guidelines and increasingly appear as operational targets for the performance of Mental Health Trusts (DoH, 2001). Although they have somewhat different policy trajectories and emphasis, 'recovery' and 'inclusion' are often conflated and advance a particular neo-liberal approach to policy and practice (Repper and Perkins, 2003). However, we argue that the way these concepts have become embedded within modern policy discourse do not tackle the particular human rights issue discussed here.

Whilst 'social inclusion' is part of a generalised strategy to combat the exclusion of marginalised groups, including, but not specifically, people with mental heath needs, 'recovery' appears to offer the specific 'mental health' aspect and 'service' element of a broader socio-economic policy agenda, which includes social inclusion as a key component. Notions of both 'recovery' and 'inclusion' have been heavily debated and contested. Yet it is possible to discern particular interpretations which have come to dominate current western policy discourse. For example, the modern version of 'recovery' is seen as transcending the old dualism between 'social' and 'medical' models by asserting a 'new' version of recovery which is not solely defined by clinical recovery (SCIE, 2007). This idea is often contrasted with medicalised notions of the 'treatment-cure' as a moment of 'turning the traditional priorities of mental health services upside down' (Shepherd et al., 2008: 4). It emphasises a person 'living a satisfying, hopeful and contributing life' irrespective of their mental heath issues (Anthony, 1993, cited in Shepherd et al., 2008: 1). Similarly, social inclusion is viewed as a 'human right' regardless of disability and as such the emphasis is on removing social barriers and obstacles to inclusion in society. On the surface, whilst these understandings may appear to advance a broadly human rights approach, it is tested on a number of levels when examining the consequences for the particular human rights issue discussed here.

First, modern notions of recovery and inclusion seem to be predicated upon a 'social model of disability', which lays the focus on overcoming social barriers and developing life opportunities rather than clinical or medical concerns. Thus recovery is perceived as occurring 'irrespective of' people's actual mental health experiences, so that discussions about the nature and treatment of the 'condition' one is supposed to be in 'recovery' from are sidestepped. The difficulty with 'bracketing out' these discussions is that the extant bio-medical orthodoxies subtending psychiatric theory and practice are left unchallenged, and, as a result, often return via the back door. Therefore, a reified concept of recovery 
may occlude the possibility of new frameworks based on pluralism and diversity, because of the prevailing dominance of bio-medical approaches to psychiatric practice (Double, 2006). As a result, many clinicians view the new concept of social recovery as a travesty of the 'real' (i.e. medical) ideal of recovery (Oyebode, 2004) and, in practice, either ignore it or adapt it to their own clinical practice.

In effect, and despite the 'social' ideal of recovery, such ideas unwittingly include a variety of implicit assumptions about what people have recovered 'from' and how they should be treated and managed (or increasingly 'self-managed'). Thus the 'widely agreed' definition of recovery (Shepherd et al., 2008) is the following:

[Recovery is] a deeply personal, unique process of changing one's attitudes, values, feelings, goals, skills and roles. It is a way of living a satisfying, hopeful and contributing life, even with the limitations caused by illness. Recovery involves the development of new meaning and purpose in one's life as one grows beyond the catastrophic effects of mental illness. (Anthony, 1993, in Shepherd et al., 2008: 1, emphasis added)

Shepherd et al. (2008) go on to reiterate four key components of recovery, three of which include reference to the individual's relationship with their 'illness', e.g. finding a new identity which incorporates illness, making sense of illness, finding a meaning in life despite illness and feeling in control of illness. Such conceptions reveal particular notions of 'adaptation' to particular ideas about 'mental illness'. Whilst these understandings are not the only version of 'recovery' on offer, we argue that they have come into prominence as part of the broader 'modernisation' agenda in mental health care and the universalist ideal of 'social inclusion'.

Similarly, whilst the recovery agenda fails to question a priori assumptions regarding illness and treatment, the inclusion agenda often fails to problematise the prevailing values and norms within 'mainstream society' (Spandler, 2007). In other words, a 'double whammy' exists in that recovery fails to question the dominant ideas about what people have recovery 'from', whilst social inclusion has no critique of that which people are supposed to be included 'in'. This is because inclusion and recovery are embedded within, and constrained by, broader mental health policies which are themselves moulded by prevailing socio-economic concerns and policies. For example, both inclusion and recovery reflect the attempt to increase the employment of people with a disability, thereby diminishing their reliance on welfare benefits. As a result, policies are increasingly focused on 'helping patients back into mainstream society' with employment being the primary means through which this is achieved (Rankin, 2005; Shepherd et al., 2008). 'Recovery' assists this focus by providing the 'service' element underpinning the socio-economic agenda of inclusion. Whilst employment may be an important goal for many people with mental health problems and there is some evidence of the link between paid work and mental health (Secker et al., 2001), we cannot assume this general association necessarily works for everyone, particularly when the workplace is often a key stressor (Spandler, 2007). Indeed recent research suggests that interpersonal support is frequently lacking in workplaces where discrimination is a reality, especially for people who experience 'psychosis' (Nithsdale et al., 2008).

In addition, it could be argued that there is a direct contradiction in policies that both seek to promote 'social inclusion' and 'recovery', primarily through paid work, and the continued promotion of long-term use of psychotropic medications which may make such participation difficult. Indeed, it could be argued that the effects of neuroleptic 
medications may actually create difficulties in pursuing and achieving personal life goals and ambitions (Bentall, 2004). For example, the psychological effects of neuroleptics can include drowsiness, tiredness, sleepiness, and restlessness as well as nervousness and lack of concentration, and can result in iatrogenic harm such as depression ('neuroleptic dysphoria') and lack of motivation ('neuroleptic induced deficit syndrome') (see Lewander, 1994).

Indeed, some of these effects may inform the apparent reluctance of people to continue to take neuroleptic medication. Yet, these policy drivers are also situated within broader mental health laws and policies which, as we have seen, focus on compulsion and treatment compliance. Indeed 'third way' policy directives under New Labour incorporate a 'new paternalism' which explicitly focuses on rights and responsibilities. Such a focus entails an individual ethic of 'self-responsibility', whereby a 'creeping conditionality' (Dwyer, 2004) is attached to the provision of welfare and service rights (Dean, 2008: 6). In this context, there is a danger that for an individual to be viewed as 'socially included' or 'recovered', they will also have to demonstrate 'illness acceptance' and/or 'treatment compliance' (Fawcett, 2007). The attendant subtext is a conscious or tacit acceptance of a new body of psychiatric knowledge which defines the parameters of both 'recovery' and 'inclusion'.

Therefore, despite the socially orientated and user-centred impetus behind the recovery and social inclusion agenda (Repper and Perkins, 2003) in practice, their implementation is based upon the acceptance of particular values of the 'social' i.e. mainstream society ('social inclusion'), and of the 'human condition', i.e. treatment and compliance ('recovery'). This concern is highlighted by increased attempts to try to 'measure' an individual's recovery and inclusion according to pre-set standards and 'recovery focused' interventions which emphasise relapse prevention, medication compliance and social skills training (Meuser et al., 2002). This issue may be particularly acute for people from black and minority ethnic communities who are more likely to be sectioned under the mental health act and receive pharmacological interventions (Fernando, 2003). In this context, it has been argued that for many people 'recovery' is more than a 'personal' or 'social' journey, but also has to be a socio-political struggle against racism and oppression (Fernando, 2008). Indeed it could be argued that the enforced unity between 'medical' and 'social' interests, manifesting as the twin pillars of 'recovery' and 'social inclusion', actually masks unresolved clinical dilemmas around medication, treatment and coercion and unresolved socio-political concerns about the vagaries of life in late modern capitalist society. In other words, the 'truce' between the 'social' and 'medical' model is only possible because of their 'incorporation' within prevailing notions of both the social and the medical.

Part of the problem arises because modern concepts of recovery and social inclusion are predicated upon the uncritical adoption of the 'social model of disability'. Crudely, the social model of disability accepts that disabled people have a physical 'impairment' but focuses attention on the various ways in which the social world needs to be opened up to create more opportunities in the environment to combat exclusion and discrimination. Although there are many parallels in the mental health field, where people labelled with psychiatric disorders do suffer stigma, oppression and discrimination, it is not clear that a social model of disability is necessarily transferable to mental health (Plumb, 2002). Not only has the social model of disability been criticised for failing to take into 
account issues of embodiment and emotionality (Shakespeare and Watson, 2002), it also poses additional challenges when transposed to the mental health field. The mental health survivor/user movement has never fully accepted that 'mental illness' can be justly compared to physical 'impairment' and recent research suggests that the 'mental illness is like any other illness' approach actually does little to address stigma and discrimination (Read et al., 2006). 'Experiential' rights-based claims problematise a purely 'social model of disability' because people who seek to extricate themselves from prevailing bio-medical definitions of 'psychosis' cannot readily mobilise this model to assert the uniqueness of particular 'extra-ordinary experiences', which, it is argued, requires particular expression and an appreciation of its meaningfulness (Plumb, 1994; Plumb, 2002).

Rather than 'bracket out' issues of diagnosis, treatment and coercion, some 'critical' practitioners and service users are attempting to develop 'new sensibilities' towards the human experience of 'madness' itself (May, 2004; Bracken, 2007; Knight, 2008). However, these 'new sensibilities' require supportive contexts in which to develop and flourish. Paradoxically, because recovery and social inclusion focuses attention away from 'services', but does not challenge the prevailing treatment agenda, it makes it more difficult to develop specifically therapeutic environments which would make non-medicationbased crisis support a viable alternative. Such services, like 'therapeutic communities' (Gale et al., 2008), based on extended periods of intensive residential or day care therapeutic support, are increasingly seen to fall foul of the prevailing 'social inclusion' and 'recovery' agenda (Spandler, 2007).

\section{Conclusion}

We have proposed that the option for people to receive non-pharmaceutical support when experiencing psychosis can be viewed as a potential 'human rights' issue, not least in relation to prevailing (and often compulsory) treatment regimes and limited access to alternative support. In particular, the claim that 'psychosis' can be re-conceptualised as part of a continuum of 'human experience' renders this demand particularly apposite. However, we have examined how dominant treatment frameworks, human rights legislation and current policy frameworks often work against these demands because they fail to challenge the dominance of bio-medical understandings of and approaches to psychiatric practice.

Ultimately, the satisfaction of these human rights-based claims may reside in a pluralist approach to practice as exemplified by organisations like the Hearing Voices Network (Knight, 2008). It is interesting to note that pluralism has been one of the more convincing explanations for higher 'recovery rates' from schizophrenia in developing countries, where a greater variety of therapeutic options are available, including support not based on pharmaceutical interventions (Halliburton, 2004). As such, a progressive human rights approach must make explicit the power imbalances within current mental health service conceptualisations, as embodied in clinical guidelines and policies, which render particular understandings and treatment approaches necessary and non-negotiable and others as either secondary or absent. It remains to be seen whether demands based on current conceptualisations of human rights will open up sufficient space for a genuinely pluralistic approach to emerge. 


\section{Acknowledgments}

Many thanks to Anne Plumb for helpful comments on this paper.

\section{Notes}

1 This paper uses 'psychosis' as a descriptive rather than diagnostic term but accepts that there are problems with its usage. The majority of research in this area has been undertaken around the diagnosis of 'schizophrenia', as it has been a particular target of social and health care policies but the argument potentially applies to any personal experience of 'psychosis' so-called.

2 In 1995 the government introduced supervised discharge which made it possible to apply some degree of coercion in the community. There are wide-spread concerns that the new Mental Health Act (2007) will accelerate this trend through extending compulsory powers further (Mental Health Alliance, 2005).

3 In England and Wales 1999, the Richardson Committee (which was set up to review the 1983 Mental Health Act) recommended that a person with capacity, who posed no risk to others, should be able to refuse treatment for 'mental disorder' (DoH, 1999a). However, this proposal was rejected by the Government (DoH, 1999c). As such, although Scotland and some areas in Canada and Australia include such 'capacity criteria', the new Mental Health Act (2007) does not (Sheehan and Molodynski, 2007).

4 See http://soteria-alaska.com/.

\section{References}

Anthony, W. A. (1993), 'Recovery from mental illness: the guiding vision of the mental health service system in the 1990s', Psychosocial Rehabilitation Journal, 16, 11-23.

Bentall, R. P. (2004), Madness Explained: Psychosis and Human Nature, London: Penguin Books.

Bentall, R. P. and Morrison, A. P. (2002), 'More harm than good: the case against using anti-psychotic drugs to prevent severe mental illness', Journal of Mental Health, 11, 4, 351-6.

Bindman, J., Maingay, S. and Szmukler, G. (2003), 'The Human Rights Act and Mental Health Legislation', British Journal of Psychiatry, 182, 91-4.

Boyle, M. 'From "schizophrenia" to "psychosis": paradigm shift or more of the same?', from Division of Clinical Psychology Annual Conference, December 2006, London.

Bracken, P. (2007), 'Beyond paradigms: promoting a recovery agenda in mental health', http://www. soteria.freeuk.com/Brackenbeyond.htm.

Brown, P. and Funk, S. (1986), 'Tardive dyskinesia: barriers to the professional recognition of iatrogenic disease', Journal of Health and Social Behaviour, 27, 116-32.

Cadman, L. J. (2006), 'A geneology of (bio) political contestation during the reform of the Mental Health Act 1983 in England and Wales', Dept Geography, University of Sheffield.

Cairns, R., Maddock, C. and Buchanan, A. (2005), 'Prevalence and predictors of mental incapacity in psychiatric in-patients', British Journal of Psychiatry, 187, 379-85.

Calton, T., Ferriter, M., Huband, N. and Spandler, H. (2008), 'A systematic review of the Soteria paradigm for the treatment of people diagnosed with schizophrenia', Schizophrenia Bulletin, 34, 1, 18192.

Calton, T. and Spandler, H. (2009), 'Minimal medication approaches to the treatment of people diagnosed with schizophrenia', Advances in Psychiatric Treatment, in press.

Campbell, P. (2000). 'A service user/survivor position on psychiatric drugs: key points for discussion', http://www.critpsynet.freeuk.com/Drugsposition.htm.

Clarke, I. (2001), Psychosis and Spirituality: Exploring the New Frontier, London: Whurr Publishers.

Day, J. C., Wood, G., Dewey, M., and Bentall, R. P. (1995), 'A self-rating scale for measuring neuroleptic side effects: validation in a group of schizophrenic patients', British Journal of Psychiatry, 166, 650653. 
Dean, H. (2008), 'Social policy and human rights: rethinking the engagement', Social Policy and Society, $7,1,1-12$.

Derbyshire Voice (2008), 'On the receiving end: the emotional and psychological impact of psychiatric assault', Derbyshire Voice, Ripley.

DoH (1999a), Review of the Mental Health Act 1983: A Report of the Expert Committee, London: Department of Health.

DoH (2001), The Journey to Recovery: The Government's vision for Mental Health Care, London: Department of Health.

DoH (2003), Building on the Best: Choice, Responsiveness and Equity in the NHS, London: Department of Health.

DoH (1999b), National Service Framework for Mental Health: Modern Standards and Service Model, London: Department of Health.

DoH (1999c), Reform of the Mental Health Act 1983: Proposals for Consultation, London: Department of Health.

Double, D. (2004), 'Suspension of doctors: medical suspensions may have ideological nature', British Medical Journal, 328, 709-10.

Double, D. B. (2006), Critical Psychiatry: The Limits of Madness, New York and Basingstoke: Palgrave Macmillan.

Dwyer, P. (2004) 'Creeping conditionality in the UK: from welfare rights to conditional entitlements', Canadian Journal of Sociology, 29, 2, 265-87.

Fawcett, B. (2007), 'Consistencies and inconsistencies: mental health, compulsory treatment and community capacity building in England, Wales and Australia', British Journal of Social Work, 37, $1027-42$.

Fernando, S. (2003), Cultural Diversity, Mental Health and Psychiatry: The Strugg/e Against Racism, Hove and New York: Brunner-Routledge.

Fernando, S. (2008). 'We Shall Overcome!', Openmind, 149, Jan/Feb, 25.

Gale, J., Realpe, J. and Pedriali, E. (2008), Therapeutic Communities for Psychosis: Philosophy, History and Clinical Practice, London: Routledge.

Gottstein, J. (2007), 'Money, rights and alternatives: enforcing legal rights as a mechanism for creating non-medical alternatives', in P. Stastny and P. Lehmann (eds), Alternatives Beyond Psychiatry, Berlin: Peter Lehmann Publishing, pp. 308-17.

Halliburton, M. (2004), 'Finding a fit: psychiatric pluralism in South India and its implications for WHO studies of mental disorder', Transcultural Psychiatry, 41, 1, 80-98.

Hopper, K., Harrison, G., Aleksander, J. and Sartiorius, N. (2004), Recovery from Schizophrenia: An International Perspective, Madison, CO: International Universities Press, Inc.

Knight, T. (2008), Beyond Belief-Alternative Ways of Working with Delusions, Obsessions and Unusual Experiences, Berlin: Peter Lehmann Publishing.

Larsen, J. A. (2004), 'Finding meaning in first episode psychosis: experience, agency and the cultural repertoire', Medical Anthropology Quarterly, 18, 4, 447-71.

Lewander, T. (1994), 'Neuroleptics and the neuroleptic-induced deficit syndrome', Acta Psychiatrica Scandinavica, 89, 8-13.

May, R. (2004), 'Making sense of psychotic experiences and working towards recovery', in J. F. M. Gleeson and P. D. McGorry (eds.), Psychological Interventions in Early Psychosis, Chichester: John Wiley \& Sons Ltd., pp. 245-60.

MCA (2005), Mental Capacity Act, London: Stationery Office.

McCabe, R. e. a. (2002), 'Engagement of patients with psychosis in consultation: conversation analytic study', British Medical Journal, 325, 1148-51.

Mental Health Alliance (2005), Towards a Better Mental Health Act, London: Mental Health Alliance.

Meuser, K. T., Corrigan, P. W., Hilton, P. W., Tansman, B., Schaub, A. and Gingerich, S. (2002), 'Illness management and recovery: a review of the research', Psychiatric Services, 51, 10, 1272 84. 
Moncrieff, J. (2007), The Myth of the Chemical Cure: A Critique of Psychiatric Drug Treatment, London: Palgrave Macmillan.

NICE (2002), Schizophrenia: Core Interventions in the Treatment and Management of Schizophrenia in Primary and Secondary Care, London: National Institute for Clincial Excellence.

Nithsdale, V., Davies, J. and Croucher, P. (2008), 'Psychosis and the experience of employment', Journal of Occupational Rehabilitation, 18, 2, 175-82.

Oyebode, F. (2004), 'Invited commentary on "the rediscovery of recovery"', Advances in Psychiatric Treatment, 10, 48-9.

Parr, H. (2008), Mental Health and Social Space: Towards Inclusionary Geographies, Oxford: Blackwell.

Plumb, A. (1999), 'New mental health legislation: a lifesaver? Changing paradigm and practice', Social Work Education, 18, 4, 459-78.

Plumb, A. (1994), Distress or Disability: A Discussion Document, Manchester: GMCDP Publications.

Plumb, A. (2002), 'Review article of From Psychiatric Patient to Citizen: Overcoming Discrimination and Social Exclusion by Liz Sayce', Social Work Education, 21, 1, 117-23.

Rankin, J. (2005), Mental Health in the Mainstream: Mental Health and Social Inclusion, London: Institute for Public Policy Research.

Read, J., Haslam, N., Sayce, L. and Davies, E. (2006), 'Prejudice and schizophreina: a review of the "mental illness is an illness like any other" approach', Acta Psychiatrica Scandinavica, 114, 5, 303-18.

Read, J., Van Os, J., Morrison, A. P. and Ross, C. A. (2005), 'Childhood trauma, psychosis and schizophrenia: a literature review with theoretical and clinical implications', Acta Psychiatrica Scandinavica, 112, 330-50.

Repper, J. and Perkins, R. (2003), Social Inclusion and Recovery: A Model for Mental Health Practice, London: Bailliere Tindall.

Rogers, A., Day, J., Williams, B., Randall, F., Wood, P., Healy, D. and Bentall, R. P. (1998), 'The meaning and management of neuroleptic medication: a study of patients with a diagnosis of schizophrenia', Social Science and Medicine, 47, 1313-23.

Rogers, A. and Pilgrim, D. (2001), Mental Health Policy in Britain, Basingstoke: Macmillan.

SCIE (2007), A Common Purpose: Recovery in Future Mental Health Services, London: Social Care Institute for Exellence.

Secker, J., Grove, B., and Seebohm, P. (2001), 'Challenging barriers to employment, training and education for mental health service users: the service users' perspective', Journal of Mental Health, 10, 4, 395 404.

Shakespeare, T. and Watson, N. (2002), 'The social model of disability: an outdated ideology?', Research in Social Science and Disability, 2, 9-28.

Sheehan, K. A. and Molodynski, A. (2007), 'Compulsion and freedom in community mental health care', Psychiatry, 6, 9, 393-8.

Shepherd, G., Boardman, J. and Slade, M. (2008), Making Recovery a Reality, London: Sainsbury Centre for Mental Health.

Spandler, H. (2007), 'From social exclusion to inclusion? A critique of the inclusion imperative in mental health', Medical Sociology online, 2, 2, 3-16.

Stastny, P. and Lehmann, P. (2007), Alternatives Beyond Psychiatry, Berlin: Peter Lehmann Publishing.

Szmukler, G. (2004), 'Mental Health Legislation in the era of community psychiatry', Psychiatry, 3, 3, $16-19$.

Thomas, S. and Thomas, T. (2004), 'The impact of the Human Rights Act 1998 on mental health care', Psychiatry, 3, 3, 20-2.

Vasak, K. (1982), The International Dimensions of Human Rights, Connecticut: Greenwood Press.

Warner, R. (2004), Recovery from Schizophrenia: Psychiatry and Political Economy, 3rd edn, London: Routledge.

Warner, R. (2008), 'Problems with early and very early intervention in psychosis', British Journal of Psychiatry Supplement, 187, 48, 104-7. 